Article

\title{
Comparative Study of Environmental Assessment Methods in the Evaluation of Resources and Environmental Carrying Capacity-A Case Study in Xinjiang, China
}

\author{
Zhiping Zhang ${ }^{1,2}$, Fuqiang Xia ${ }^{1,2, *}$, Degang Yang ${ }^{1,2, *} \mathbb{C}$, Yufang Zhang ${ }^{1,2}$, Tianyi Cai ${ }^{1,2}$ and \\ Rongwei $\mathrm{Wu}^{1,2}$ (D) \\ 1 State Key Laboratory of Desert and Oasis Ecology, Xinjiang Institute of Ecology and Geography, Chinese \\ Academy of Science, Urumqi 830011, China \\ 2 University of Chinese Academy of Science, Beijing 100049, China \\ * Correspondence: xiafq@ms.xjb.ac.cn (F.X.); dgyang@ms.xjb.ac.cn (D.Y.); Tel.: +86-0991-782-7314 (F.X.)
}

Received: 1 July 2019; Accepted: 22 August 2019; Published: 27 August 2019

\begin{abstract}
Scientifically assessing the environmental carrying capacity (ECC) based on an evaluation of environmental quality standards (EQSs) holds great significance for establishing a long-term monitoring and early warning mechanism for resources and environmental carrying capacity (RECC) and for coordinating the sustainable development of ecological environments and regional economies. However, it remains unclear whether the evaluation of EQSs based on the short board effect is suitable for environmental assessments under different natural environments. In this research, Xinjiang is used as a case study. Based on the evaluation of EQSs, the atmospheric environmental carrying capacity (AECC), water environmental carrying capacity (WECC) and comprehensive environmental carrying capacity (CECC) are assessed using the short board effect and the weighted average. Additionally, the suitability of ECC evaluation in RECC evaluation is discussed. The results show the following: (1) In the atmosphere, the overload of inhalable particles $\left(\mathrm{PM}_{10}\right)$ and fine particulate matter $\left(\mathrm{PM}_{2.5}\right)$ is more serious, while in water, the overload of total nitrogen (TN) is more serious. (2) The percentages of the AECC, WECC and CECC in overloaded counties and cities based on the short board effect are $84 \%, 45 \%$, and $51 \%$, respectively, while the percentages based on the weighted average are $32 \%, 6 \%$ and $7 \%$, respectively. (3) The extreme effects of a single pollutant can be eliminated by the weighted average, which is more suitable for environmental assessments in Xinjiang. (4) In evaluating RECC monitoring and early warning systems, weighted average evaluation is used to assess the elements, and short board effect evaluation is used in the comprehensive integration to prevent the influence of the amplification of a single index. Thus, the interference of non-key factors in the regional system on the final evaluation results is reduced.
\end{abstract}

Keywords: resources and environmental carrying capacity; environmental quality standards; short board effect; weighted average; Xinjiang

\section{Introduction}

Since the beginning of the industrial era, the global population and economy have continued to grow. Energy resources have been excessively exploited, aggravating air pollution and water pollution. The pollution of these two components of the environment has important impacts on climate and health [1,2] and on social and economic development [3-5]. Especially in developing countries, environmental pollution has increasingly become an important factor that cannot be ignored. With the rapid development of the social economy, China's environmental problems have become increasingly 
prominent since the country's reform and opening. The Action Plan for Water Pollution Prevention and Control, issued by the State Council in 2015, indicated that "China's industrial, agricultural and domestic pollution discharge load is large, the total amount of chemical oxygen demand emissions is 2294.6 thousand tons, and the total amount of ammonia nitrogen emissions is 238.5 thousand tons, far exceeding the environmental capacity". According to the China Environmental Bulletin of 2017, out of 338 cities in China, $27.2 \%$ met the environmental air quality standards, and $72.8 \%$ exceeded the standards. Clearly, environmental pollution has become an important bottleneck restricting China's economic and social development and is seriously affecting the process of modernization.

With the occurrence of global problems such as resource exhaustion and environmental deterioration, people have gradually begun to realize the contradictions and have become aware of their dependence on the ecological environment. Therefore, research on the environmental carrying capacity (ECC) has emerged over time. The carrying capacity concept has developed from physical concepts. In 1798, Malthus proposed the concept of the "population carrying capacity" [6]. In 1921, Parker and Burgess extended the concept to human ecology [7], prompting different scholars to define and apply the ECC in different ways [8-10]. As an important basis for measuring the degree of coordinated development of the human-land relationship in a country or region [11], the ECC serves as a macro criterion for coordinating the environment and the social economy [12]; this idea has been applied to coordinate the stable development of the environment, the economy and society.

Currently, there is no consensus on ECC assessment methods. The widely used assessment methods include comprehensive evaluations consisting of index systems [13-17], ecological footprints [18-20], energy analysis [21], system dynamics [22,23], optimization decision models [24-26] and load carrying ratio evaluations [27]. For example, Davies and Simonovic (2011) verified the value of wastewater treatment and reuse based on an in-depth understanding of the nature and structure of the relationship between water resources and socioeconomic and environmental changes using a comprehensive evaluation model that was based on system dynamics [22]. Zhang et al. (2019) assessed the resources and environmental carrying capacity of 36 large cities in China from 2010 to 2016 by constructing an RECC evaluation index system, which found that the RECC of Beijing, Shanghai, Guangzhou and Shenzhen had already been exceeded [17]. Pandey et al. (2011) constructed a framework and measured the adaptability of water resource systems across basins at different spatial and temporal scales in the Bagmati River Basin (BRB) in Nepal [28]. The methods mentioned above have made important contributions to ECC assessments. However, there are some gaps in the scope, operability and applicability of the assessment methods. For example, the results of comprehensive evaluations consisting of index systems are usually a single index and are relatively abstract, which makes it difficult to effectively guide specific management practices [29]. System dynamics has some advantages in dealing with nonlinear problems, but its optimization function is relatively weak [30,31]. Moreover, it is difficult to popularize and apply the above evaluations because of the level of technical knowledge required, data support limitations and other factors [18,20,25].

To realize the sustainable development of regional economies and environments, the Chinese government issued the "Technical Method for the Monitoring and Early Warning of Resources and Environmental Carrying Capacity (Trial Implementation) (No. 2043 of the National Development and Reform Commission (NDRC)" (hereinafter referred to as the "Technical Method"), and the State Council of China issued the "Suggestions on Establishing a Long-term Mechanism for the Monitoring and Early Warning of Resources and Environmental Carrying Capacity" (hereinafter referred to as the "Suggestions"). Regular global and specific regional assessments, the real-time monitoring of key regional developments, and guidance for and constraints on planning economic and social development in strict accordance with the RECC of different regions in China are required. In addition, an ECC assessment based on environmental quality standards (EQSs) is proposed by the "Technical Method". This method reflects pollutant concentrations that exceed the standard, where the annual average concentration values of major pollutants determined by monitoring are compared with the current national EQS. Short board effect theory is used to integrate the comprehensive environmental 
carrying capacity based on the index of concentrations that exceed the standards of major pollutants in the atmosphere and in water. In short board effect theory, only by grasping the main contradiction of the problem can it be solved. However, China is vast in area, and its natural environment greatly varies. Whether short board effect-based assessments of EQSs can be applied to environmental assessment under different natural environments remains to be further studied. In the whole RECC evaluation system, methods based on the short board effect are used only in ECC evaluation, which easily strengthens the restrictive factors. In contrast, methods based on the weighted average weaken the constraints. The ECC is an important RECC component; thus, further developing technical methods for ECC evaluation is important for establishing RECC monitoring and early warning systems in China. These developments also hold great significance for optimizing spatial planning, solving air and water pollution problems and promoting sustainable development [30,32,33].

This paper uses Xinjiang as a case study. Based on the evaluation of EQSs, short board effect evaluation and weighted average evaluation are used to assess the atmospheric environmental carrying capacity (AECC), water environmental carrying capacity (WECC) and comprehensive environmental carrying capacity (CECC) to improve resources and environmental carrying capacity (RECC) monitoring and early warning technology systems, to improve the scientific basis of policy formulation and to realize regional sustainable development. These improvements will thus develop and promote the formation of an ecological society.

\section{Materials and Methods}

\subsection{Study Area}

Xinjiang, China, which is in the middle of the Eurasian continent $\left(34.25^{\circ} \mathrm{N}-49.17^{\circ} \mathrm{N}\right.$, $73.33^{\circ}$ E-96.42 ${ }^{\circ}$ E) (Figure 1), is far from the ocean, lacks water resources, and has a total area of 1,665,000 square kilometers [34]. This region is a typical mountain basin system and is formed by "three mountain peaks and two basins". Xinjiang has a typical temperate continental climate, with an average annual precipitation of 100-230 mm and an average annual evaporation of 2000-3000 mm. This region is a typical arid and ecologically fragile area in China, and because of its vulnerability and sensitivity, it is more susceptible to human activities [35,36]. Overgrazing, excessive reclamation and urbanization have accelerated, and the ecological environment of Xinjiang has been damaged as a result $[37,38]$. In particular, pollution of the atmosphere and water in Xinjiang has become increasingly serious [39-41]. Although Xinjiang is located on the northwest border of China, it has a special strategic position. Xinjiang is at the forefront of China's move towards Central Asia, South Asia, West Asia and even Europe. Xinjiang is also the "core area" of the current construction of China's Silk Road Economic Belt. The destruction of the ecological environment and environmental pollution will directly affect the sustainable development of Xinjiang's economy and society and the implementation of the "The Belt and Road Initiative" strategy. Objectively evaluating Xinjiang's ECC is conducive to grasping the contradiction between the coordinated development of Xinjiang's economy, society and ecological environment and the promotion of sustainable development.

\subsection{Data Sources and Processing}

The environmental data on atmospheric and water (surface water) quality in Xinjiang were obtained from the Xinjiang Environment Department and the Xinjiang Hydrological Bureau. The specific data included the annual average mass concentrations of atmospheric pollutants, namely, sulfur dioxide $\left(\mathrm{SO}_{2}\right)$, nitrogen dioxide $\left(\mathrm{NO}_{2}\right)$, carbon monoxide $(\mathrm{CO})$, ozone $\left(\mathrm{O}_{3}\right)$, fine particulate matter $\left(\mathrm{PM}_{2.5}\right)$, and inhalable particles $\left(\mathrm{PM}_{10}\right)$. These data also included the average annual concentrations of water pollutants, namely, dissolved oxygen (DO), the permanganate index $\left(\mathrm{COD}_{\mathrm{Mn}}\right)$, chemical oxygen demand $\left(\mathrm{COD}_{\mathrm{Cr}}\right)$, biochemical oxygen demand $\left(\mathrm{BOD}_{5}\right)$, ammonia nitrogen $\left(\mathrm{NH}_{3}-\mathrm{N}\right)$, total phosphorus (TP) and total nitrogen (TN). For its analysis, this paper takes 2015 as the study period. Furthermore, 
19 counties and cities were included in the AECC assessment, and 89 counties and cities were included in the WECC assessment (Figure 1).

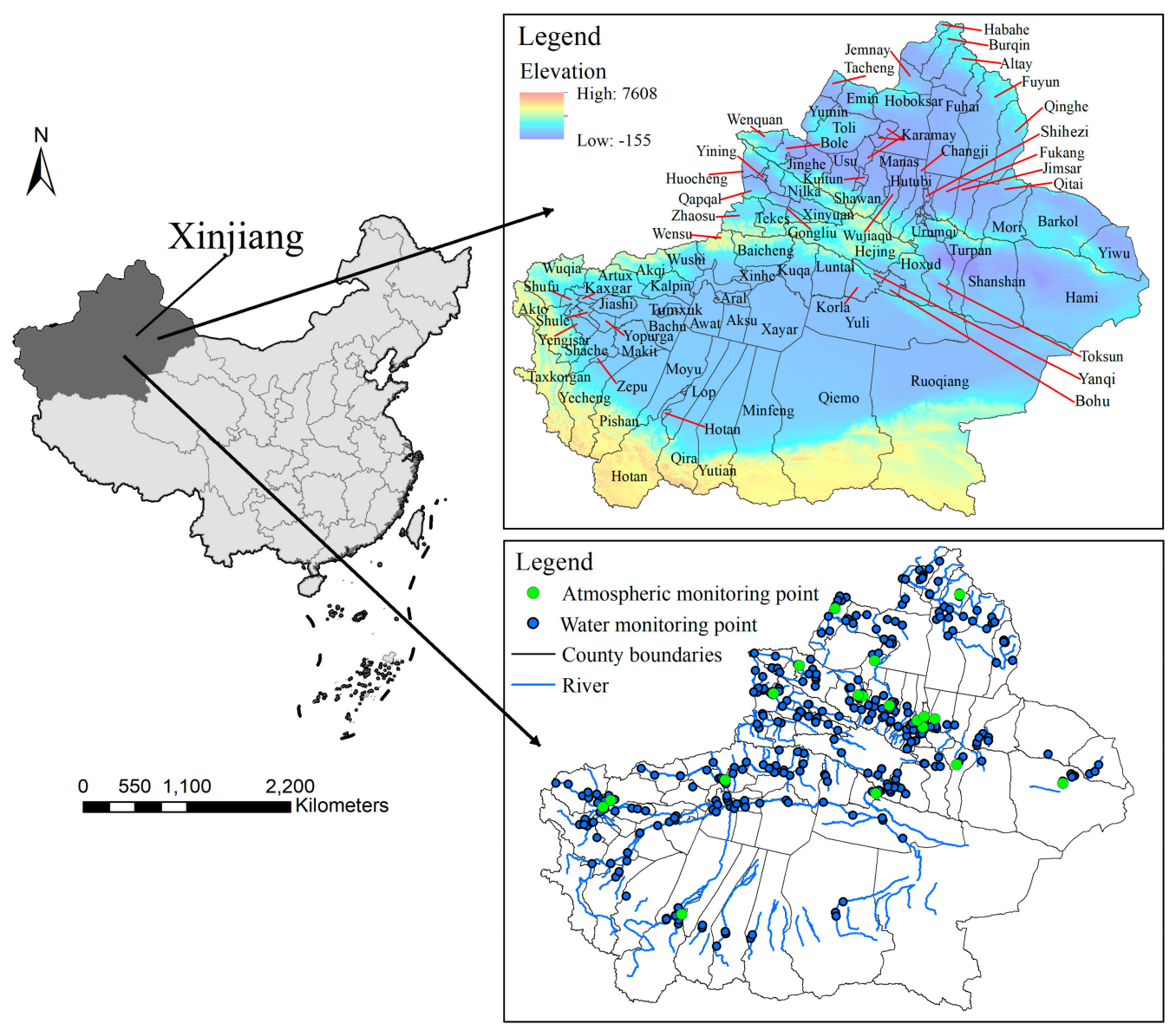

Figure 1. Map of study area (location map, topographic map (including counties and cities) and monitoring point map).

\subsection{ECC Evaluation Based on EQSs}

The EQS-based ECC evaluation included three parts: first, an evaluation of the individual air and water pollutants; second, an evaluation of the AECC and WECC; and third, a comprehensive evaluation of the environment. The short board effect and weighted average were used for the comparative analysis of the latter two parts.

\subsubsection{Assessment of the Individual Pollutants}

\section{- Atmospheric Pollutants}

The standard limits of pollutants, including those from various social and economic activities of humans (the secondary standards of the concentration limits of the various air pollutants stipulated in the Environmental Air Quality Standard (GB3095-2012) [42] were adopted), are used to characterize the thresholds that environmental systems can withstand. The calculation formula for the over standard index of the various pollution indices in different regions is as follows:

$$
R g_{i j}=C_{i j} / S_{i}-1
$$

In the formula, $\operatorname{Rg}_{i j}$ is the over standard index of atmospheric pollutant concentration $i$ in region $j$; $C_{i j}$ is the annual average concentration detection value of a pollutant ( $\mathrm{CO}$ is the 95th percentile of the 24-h average concentration; $\mathrm{O}_{3}$ is the 90 th percentile of the daily maximum 8-h average concentration); 
$S_{i}$ is the second standard limit of a pollutant concentration (Table 1); and $i=1,2, \ldots, 6$, corresponding to $\mathrm{SO}_{2}, \mathrm{NO}_{2}, \mathrm{PM}_{10}, \mathrm{CO}, \mathrm{O}_{3}$, and $\mathrm{PM}_{2.5}$, respectively.

Table 1. Secondary Standard Table for the Concentration Limits of Atmospheric Pollutants.

\begin{tabular}{ccccccc}
\hline Contaminant & $\mathbf{S O}_{\mathbf{2}}$ & $\mathbf{N O}_{\mathbf{2}}$ & $\mathbf{C O}$ & $\mathbf{O}_{\mathbf{3}}$ & $\mathbf{P M}_{\mathbf{2 . 5}}$ & $\mathbf{P M}_{\mathbf{1 0}}$ \\
\hline $\begin{array}{c}\text { Standard limit } \\
\text { Unit }\end{array}$ & $\begin{array}{c}60 \\
\mu \mathrm{g} / \mathrm{m}^{3}\end{array}$ & $\begin{array}{c}40 \\
\mu \mathrm{g} / \mathrm{m}^{3}\end{array}$ & $\begin{array}{c}4 \\
\mathrm{mg} / \mathrm{m}^{3}\end{array}$ & $\begin{array}{c}160 \\
\mu \mathrm{g} / \mathrm{m}^{3}\end{array}$ & $\begin{array}{c}35 \\
\mu \mathrm{g} / \mathrm{m}^{3}\end{array}$ & $\begin{array}{c}70 \\
\mu \mathrm{g} / \mathrm{m}^{3}\end{array}$ \\
\hline
\end{tabular}

- Water Pollutants

The difference between the annual average concentration of the main pollutants in each control section and a certain water quality standard limit of the pollutants was taken as the excess quantity of the water pollutants. The standard limit refers to the surface water environmental quality standard (GB38382002) [43], and the standard value was unified with class III (Table 2). The calculations are as follows:

when $i=1$,

$$
R w_{i j k}=1 /\left(C_{i j k} / S_{i k}\right)-1
$$

when $i=2-7$,

$$
\begin{aligned}
& R w_{i j k}=C_{i j k} / S_{i k}-1 \\
& R w_{i j}=\sum_{k=1}^{N_{j}} R w_{i j k} / N_{j}
\end{aligned}
$$

\begin{tabular}{|c|c|c|c|c|c|c|c|}
\hline Contaminants & DO & $\mathrm{COD}_{\mathrm{Mn}}$ & $\operatorname{COD}_{\mathrm{Cr}}$ & $\mathrm{BOD}_{5}$ & $\mathrm{NH}_{3}-\mathrm{N}$ & TP & $\mathbf{T N}$ \\
\hline $\begin{array}{c}\text { Standard limits } \\
\text { unit }\end{array}$ & $\begin{array}{c}5 \\
\mathrm{mg} / \mathrm{L}\end{array}$ & $\begin{array}{c}6 \\
\mathrm{mg} / \mathrm{L}\end{array}$ & $\begin{array}{c}20 \\
\mathrm{mg} / \mathrm{L}\end{array}$ & $\begin{array}{c}4 \\
\mathrm{mg} / \mathrm{L}\end{array}$ & $\begin{array}{c}1 \\
\mathrm{mg} / \mathrm{L}\end{array}$ & $\begin{array}{c}0.2 \\
\mathrm{mg} / \mathrm{L}\end{array}$ & $\begin{array}{c}1 \\
\mathrm{mg} / \mathrm{L}\end{array}$ \\
\hline
\end{tabular}

Table 2. Standard Limits of Water Quality for the Water Pollutants (Class III).

In the formula, $R w_{i j k}$ is the index of the excessive concentration of water pollutants in item $i$ of section $k$ of region $j ; R w_{i j}$ is the index of the excessive concentration of water pollutants in item $i$ of region $j ; C_{i j k}$ is the annual monitoring value of the water pollutant concentration in item $i$ of section $k$ of region $j$; and $S_{i k}$ is the water quality standard limit of the water pollutant in item $i$ of section $k$ (Table 2). The variable $i$ equals $1,2, \ldots, 7$ and corresponds to $\mathrm{DO}, \mathrm{COD}_{\mathrm{Mn}}, \mathrm{BOD}_{5}, \mathrm{COD}_{\mathrm{Cr}}, \mathrm{NH}_{3}-\mathrm{N}, \mathrm{TN}$, and TP, respectively; $k$ is the control section, and $k=1,2, \ldots, \mathrm{N}_{j} ; \mathrm{N}_{j}$ denotes the number of control surfaces in region $j$. Here, when $k$ is the river control section, $R w_{i j k}$ is calculated as $i=1,2, \ldots, 5$, and 7 ; when $k$ is the control section of lakes and reservoirs, $R w_{i j k}$ is calculated as $i=1,2, \ldots$, and 7 .

\subsubsection{Assessment of the AECC}

\section{- Short Board Effect}

Based on Formulas (1) and (5), which is under the short board effect, is obtained as follows. $\mathrm{Rg}_{j}$ is the index of the excessive atmospheric pollutant concentration in region $j$, and its value is the maximum of the index of the excessive atmospheric pollutant concentration.

$$
R g_{j}=\max \left(R g_{i j}\right)
$$

- Weighted Average

Based on Formulas (1) and (6), which is under the weighted average, is obtained as follows. $\mathrm{Rg}_{j}{ }^{\prime}$ is the index of the excessive atmospheric pollutant concentration in region $j$, and its value is the average 
value of the sum of the over standard indices of all kinds of atmospheric pollutants. $N_{i}$ represents the quantity of atmospheric pollutants. Different pollutants have different impacts on the environment, and the same pollutant has different impacts in different geographical environments [44-47]. Therefore, the weighted method to define the relative importance of each pollutant is more in line with the local actual situation. However, the mechanism of environmental impact of different pollutants in arid regions has not been clarified. Therefore, this study assumes that the weights of air and water pollutants in Xinjiang are 1.

$$
R g_{j}^{\prime}=\left(\sum_{i=1}^{6} W_{i} * R g_{i j}\right) / N_{i}
$$

\subsubsection{Assessment of the WECC}

\section{- Short Board Effect}

Based on Formulas (2)-(4) and (8), which is under the short board effect, is obtained as follows. $R w_{j k}$ is the index of the water pollutant concentration exceeding the standard in section $\mathrm{k}$ of region $j$; $R w_{j}$ is the index of the water pollutant concentration exceeding the standard in region $j$.

$$
\begin{gathered}
R w_{j k}=\max _{i}\left(R w_{i j k}\right) \\
R w_{j}=\sum_{k=1}^{N_{j}} R w_{j k} / N_{j}
\end{gathered}
$$

- Weighted Average

Based on Formulas (2)-(4) and (10), which is under the weighted average, is obtained. $R w_{j k}{ }^{\prime}$ is the index of the water pollutant concentration exceeding the standard in section $k$ of region $j ; R w_{j}{ }^{\prime}$ is the index of the water pollutant concentration exceeding the standard in region $j ; N_{i}$ is the quantity of the water pollutant.

$$
\begin{gathered}
R w_{j k}=\left(\sum_{i=1}^{7} W_{i} * R w_{i j k}\right) / N_{i} \\
R w_{j}^{\prime}=\sum_{k=1}^{N_{j}} R w_{i j k} / N_{j}
\end{gathered}
$$

\subsubsection{Assessment of the CECC}

- Short Board Effect

Based on Formulas (5), (8) and (11), which is under the short board effect, is obtained as follows. $R_{j}$ is the comprehensive over standard index of the pollutant concentration in region $j$.

$$
R_{j}=\max \left(R g_{j}, R w_{j}\right)
$$

\section{- Weighted Average}

Based on Formulas (6), (10) and (12), which is under the weighted average, is obtained as follows. In the formula, $R_{j}{ }^{\prime}$ is the comprehensive over standard index of region $j ; R g_{j}^{\prime}$ is the over standard index of the atmospheric pollutant concentration of regional $j ; N$ is the number of element layers; and $R w_{j}{ }^{\prime}$ is the over standard index of the water pollutant concentration of region $j$. Specifically, if both $R_{j}{ }^{\prime}$ and $R w_{j}{ }^{\prime}$ exist, then this formula is used; otherwise, the original formula, Formula (11), is used.

$$
R_{j}^{\prime}=\left(R g_{j}^{\prime}+R w_{j}^{\prime}\right) / N
$$

\subsubsection{Threshold and Important Parameters}

According to the comprehensive excess index of the pollutant concentrations, the evaluation results are divided into three types: pollutant concentration overloaded, critically overloaded and 
not overloaded. The smaller the pollutant concentration overload index is, the stronger the ability of the regional environmental system to support the social and economic system. Usually, when $R_{j}>0$, the pollutant concentration is in the overloaded state; when $R_{j}$ is between -0.2 and 0 , the pollutant concentration is in the critically overloaded state; and when $R_{j}<-0.2$, the pollutant concentration is in the not overloaded state.

\section{Results and Discussion}

\subsection{Assessment of the Individual Pollutants}

\subsubsection{Atmospheric Pollutants}

The results of a single-index evaluation of the atmospheric pollutants based on Formula (1) are shown in Figure 2. The single indicators that caused serious overloading of the atmospheric pollutants in Xinjiang were $\mathrm{PM}_{10}$ and $\mathrm{PM}_{2.5}$, while $\mathrm{SO}_{2}, \mathrm{NO}_{2}, \mathrm{CO}$ and $\mathrm{O}_{3}$ had lower impacts on the air pollution level.

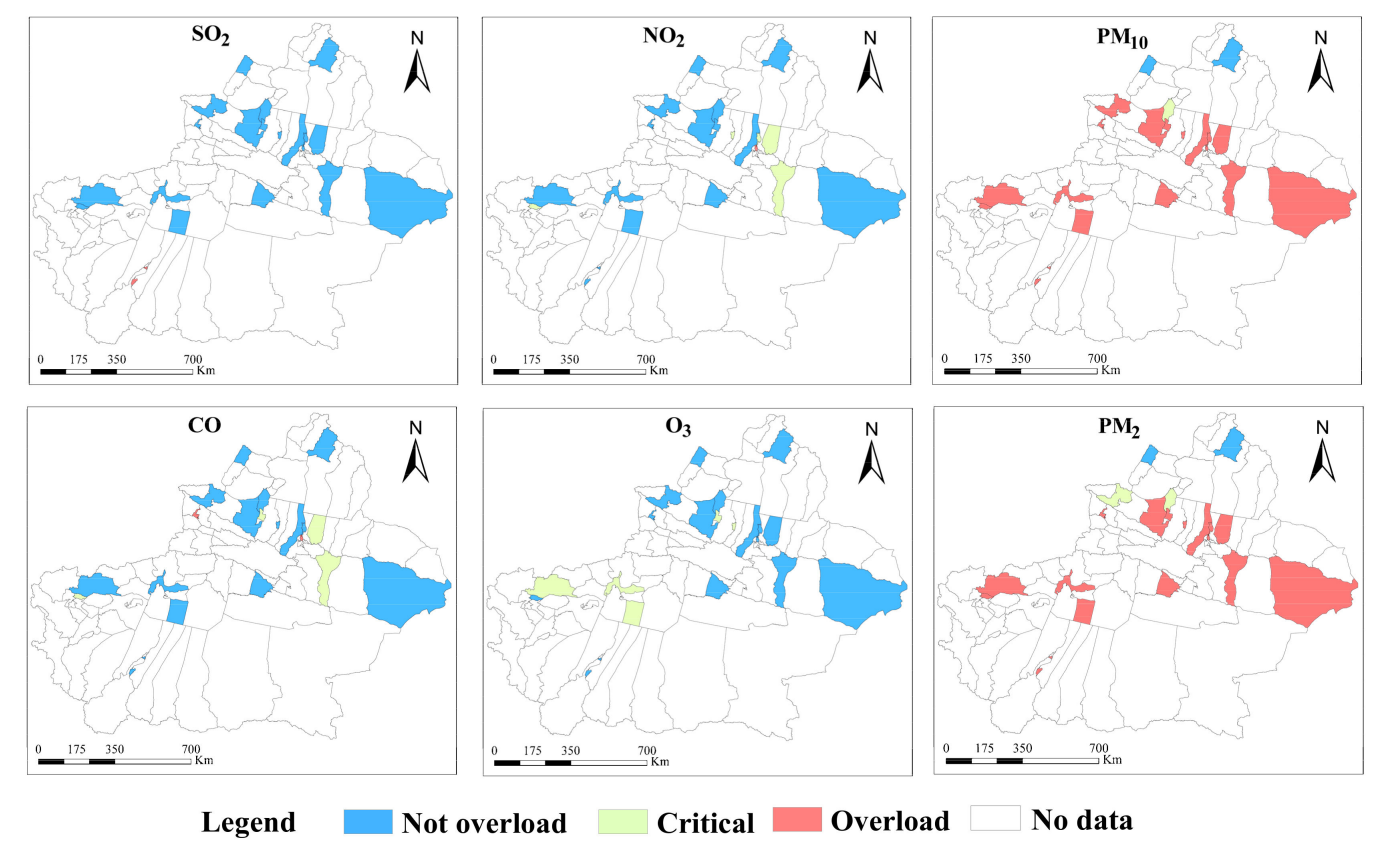

Figure 2. Results of single-index evaluations of the air pollutants.

Among the 19 counties and cities with monitoring points in Xinjiang, the $\mathrm{SO}_{2}$ concentration situation was relatively good (Figure 2- $\mathrm{SO}_{2}$ ). The percentage of overloaded counties and cities was $5 \%$, i.e., Hetian City; the remaining 18 counties and cities were not overloaded. The $\mathrm{NO}_{2}$ concentration was also relatively good (Figure 2- $\mathrm{NO}_{2}$ ). The percentage of overloaded counties and cities was $5 \%$, i.e., the Xinshi District. In addition, there were seven critically overloaded counties and cities, namely, Fukang City, Shihezi City, Changji City, Wujiaqu City, Yining City, Kashi City and Turpan City; the other 11 counties and cities were not overloaded. The overall environmental situation of $\mathrm{O}_{3}$ was quite stable (Figure 2-O $\mathrm{O}_{3}$ ). Except for four cities that were critically overloaded (Kuytun City, Shihezi City, Aksu City, and Artux City), the remaining 15 counties and cities were not overloaded. Eleven percent of the counties and cities had overloaded $\mathrm{CO}$ concentration ratios (Figure 2-CO); these overloaded areas were Yining City and the Xinshi District. Furthermore, there were four critically overloaded counties and cities, namely, Kuytun City, Fukang City, Kashi City, and Turpan City; the other 12 counties and cities were not overloaded. The $\mathrm{PM}_{10}$ concentration overload situation was very serious, with an overloaded county rate of 78\% (Figure 2-PM $\mathrm{PM}_{10}$ ). Except for the Karamay District (critically overloaded) and Altay City and Tacheng City (not overloaded), the other counties and cities were all overloaded. 
The $\mathrm{PM}_{2.5}$ concentration overload situation was more serious, with an overloaded county rate of $84 \%$ (Figure 2-PM 2.5 ). Except for Altay City and Tacheng City (not overloaded) and the Karamay District and Bole City (critically overloaded), the other counties and cities were overloaded.

\subsubsection{Water Pollutants}

The results of a single-index evaluation of the water pollutants based on Formulas (2)-(4) are shown in Figure 3. Five counties and cities had overloaded DO concentrations, namely, Barkol Kazak Autonomous County (BKAC), Xinyuan County, Yining City, Zepu County and Akqi County. Moreover, eight counties and cities were critically overloaded: Altay City, Bole City, Jinghe County, Manas County, Awat County, Hotan County, Lop County and Yutian County. In contrast, the other 76 counties and cities were not overloaded (Figure 3-DO). Two counties and cities were overloaded with $\mathrm{COD}_{\mathrm{Mn}}$, namely, the Midong District and BKAC; in addition, two counties and cities were critically overloaded.

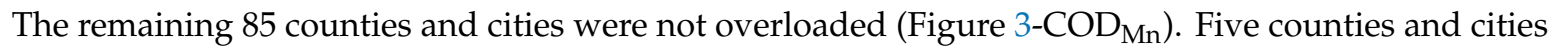
were overloaded with $\mathrm{COD}_{\mathrm{Cr}}$, namely, the Midong District, BKAC, Fuhai County, the Shuimogou District and Bohu County, and two counties were critically overloaded, namely, Awat County and Akqi County. The remaining 82 counties and cities were not overloaded (Figure 3-COD $\mathrm{Cr}_{\mathrm{Cr}}$ ). Two counties were overloaded with $\mathrm{NH}_{3}-\mathrm{N}$, and the remaining 86 counties and cities were not overloaded (Figure 3- $\mathrm{NH}_{3}-\mathrm{N}$ ). Except for the Midong District and BKAC (overloaded) and Awati County and Bohu County (critically overloaded), the other 85 counties and cities were not overloaded with $\mathrm{BOD}_{5}$ (Figure 3-BOD ${ }_{5}$ ). Except for the Midong District (overloaded) and Awat County, Kashi City and BKAC (critically overloaded), the other 85 counties and cities were not overloaded with TP (Figure 3-TP). Forty counties and cities were overloaded with TN; 15 counties and cities were critically overloaded, and 30 counties and cities were not overloaded (Figure 3-TN).

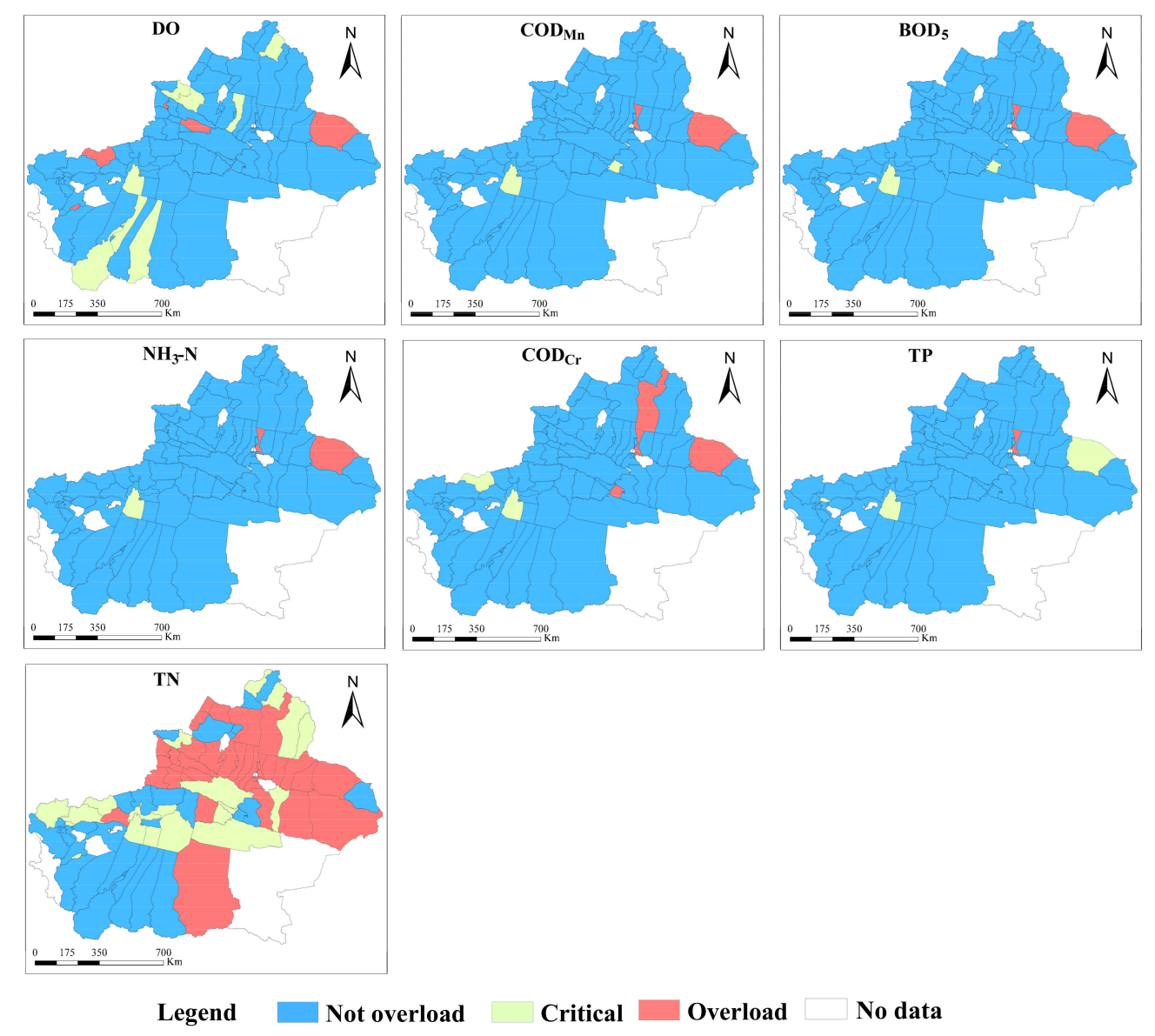

Figure 3. Results of the single-index evaluations of the water pollutants. 
The single index that caused the concentrations of the water pollutants to seriously exceed the standard in Xinjiang was TN, accounting for $45 \%$ of all counties and cities. The counties and cities that were overloaded with TN were mainly distributed in the northern Xinjiang area, such as the Yili River Valley and the northern slope economic belt of the Tianshan Mountains. In addition, the DO, $\mathrm{COD}_{\mathrm{Mn}}$, $\mathrm{BOD}_{5}, \mathrm{NH}_{3}-\mathrm{N}, \mathrm{CODCr}$ and TP situations were relatively good. Only a few counties and cities were overloaded, including BKAC, Aksu City, Bohu County and the Midong District. Among them, BKAC was the most affected by the various water pollutants. The overload indices of the seven pollutants were $7.82(\mathrm{DO}), 7.00\left(\mathrm{COD}_{\mathrm{Mn}}\right), 26.35\left(\mathrm{COD}_{\mathrm{Cr}}\right), 24.72\left(\mathrm{BOD}_{5}\right), 2.55\left(\mathrm{NH}_{3}-\mathrm{N}\right), 0.03(\mathrm{TP})$ and $1.85(\mathrm{TN})$.

\subsection{Assessment of the AECC}

\subsubsection{Short Board Effect}

Based on Formula (5), the concentration indices of the six air pollutants were calculated and used to characterize the AECC. The calculation results are shown in Figure $4-\mathrm{Rg}_{j}$. In the 19 counties and cities with monitoring points, the AECC overload situation was very serious. Overloads were found in $84 \%$ of the counties and cities with monitoring points in Xinjiang. The 16 overloaded counties and cities were Wusu City, Bole City, Yining City, Kuytun City, Shihezi City, Changji City, Fukang City, Wujiaqu City, Turpan City, Hami City, Aksu City, Kashgar City, Atushi City, Korla City, the Xinshi District and Hetian City. The Karamay District was critically overloaded, while Altay City and Tacheng City were not overloaded.
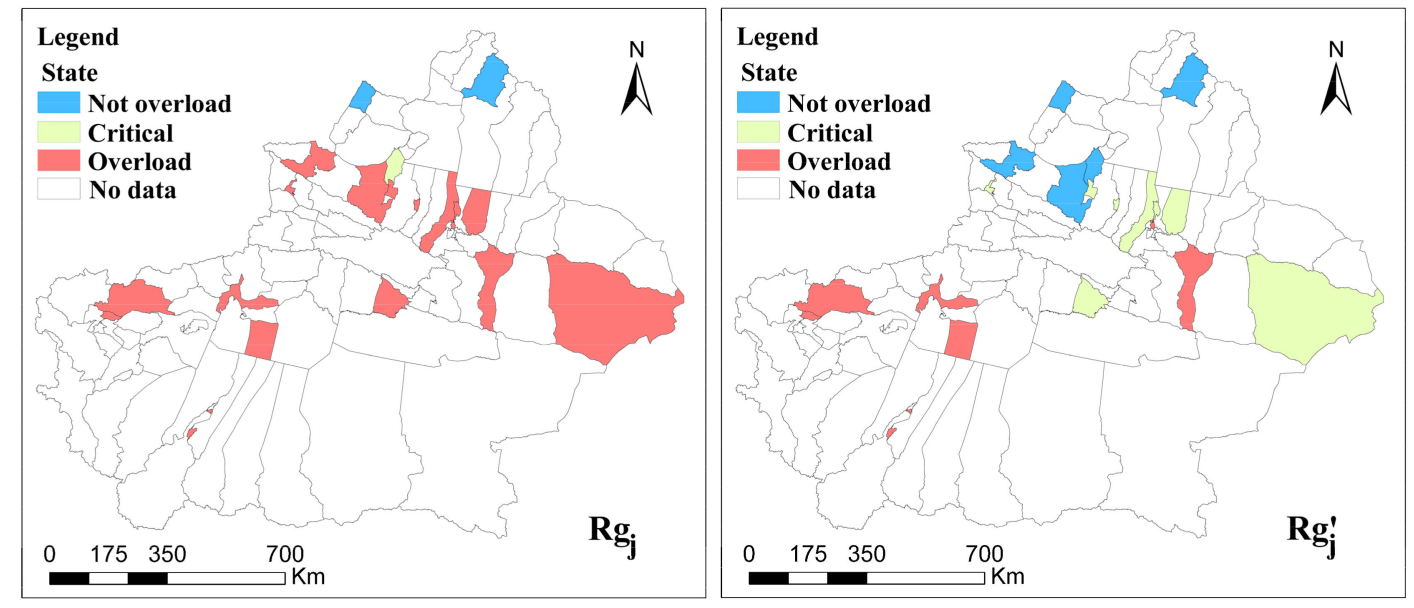

Figure 4. Assessment results of the AECC. $\operatorname{Rg}_{j}$ is the AECC based on the short board effect, while $\operatorname{Rg}_{j}{ }^{\prime}$ is the AECC based on the weighted average.

\subsubsection{Weighted Average}

Based on Formula (6), the concentration indices of the six air pollutants were calculated and used to characterize the AECC. The calculation results are shown in Figure 4- $\mathrm{Rg}_{j}{ }^{\prime}$. Among the 19 counties and cities with atmospheric monitoring points, Tacheng City and Altay City had relatively good environmental conditions, while southern Xinjiang had poor environmental quality and serious air pollution. Thirty-two percent of the counties and cities in Xinjiang were overloaded, including the Xinshi District, Atushi City, Turpan City, Aksu City, Hetian City and Kashgar City. In addition, there were eight critically overloaded counties and cities: Shihezi City, Hami City, Korla City, Kuytun City, Changji City, Yining City, Fukang City and Wujiaqu City. Five counties and cities were not overloaded: Tacheng City, Altay City, Bole City, Usu City and the Karamay District. 


\subsubsection{Comparative Analysis}

Based on the short board effect, regarding the AECC, the percentages of overloaded, critically overloaded and not overloaded counties and cities were $84 \%, 5 \%$ and $11 \%$, respectively. Combined with the results in Figure 2, $\mathrm{PM}_{2.5}$ and $\mathrm{PM}_{10}$ were the main factors of the AECC overload in Xinjiang. However, the high $\mathrm{PM}_{2.5}$ and $\mathrm{PM}_{10}$ levels in Xinjiang were the result of natural factors, such as drought, low rain amounts, sparse vegetation, the extensive Gobi Desert and more wind [48-50], with human activities having a lower impact [51,52]. At the same time, some environmental experts in Xinjiang have pointed out that the monitoring data on $\mathrm{PM}_{2.5}$ and $\mathrm{PM}_{10}$ in Xinjiang are too high to truly evaluate the air quality of arid regions [53-55]. The results of the weighted average evaluation showed that the percentages of overloaded, critically overloaded and not overloaded counties and cities were $32 \%, 42 \%$ and $26 \%$, respectively. Compared with the short board effect, the percentages of overloaded counties and cities based on the weighted average decreased by $62 \%$, which also eliminated the extreme effects of $\mathrm{PM}_{2.5}$ and $\mathrm{PM}_{10}$. In addition, during the heating period, the main methods of burning coal and firewood and the inadequate treatment technology were the main reasons for the $\mathrm{SO}_{2}$ and $\mathrm{NO}_{2}$ levels exceeding the standards in some areas of Xinjiang. Engineering construction, motor vehicle exhaust emissions and dust also caused compound pollution aggravation in the atmospheric environment.

\subsection{Assessment of the WECC}

\subsubsection{Short Board Effect}

According to Formulas (7) and (8), the excess indices of seven kinds of water pollutant concentrations in Xinjiang were calculated and used to characterize the WECC. The calculation results are shown in Figure 5-Rw $\mathrm{R}_{j}$. Among the 89 counties and cities with water monitoring points, the state of WECC overload was very serious. Overloaded counties and cities with water monitoring points in Xinjiang accounted for $45 \%$ of the total. There were 40,11 and 38 overloaded, critically overloaded and not overloaded counties and cities, respectively. In addition, the WECC overloaded counties and cities were mainly distributed in the northern Xinjiang area, such as the Yili River Valley and Wuchang Urban Agglomeration. The critically overloaded counties and cities were mainly distributed in the Hetian and Kashgar areas, while the not overload counties and cities were mainly distributed in the Aksu area.
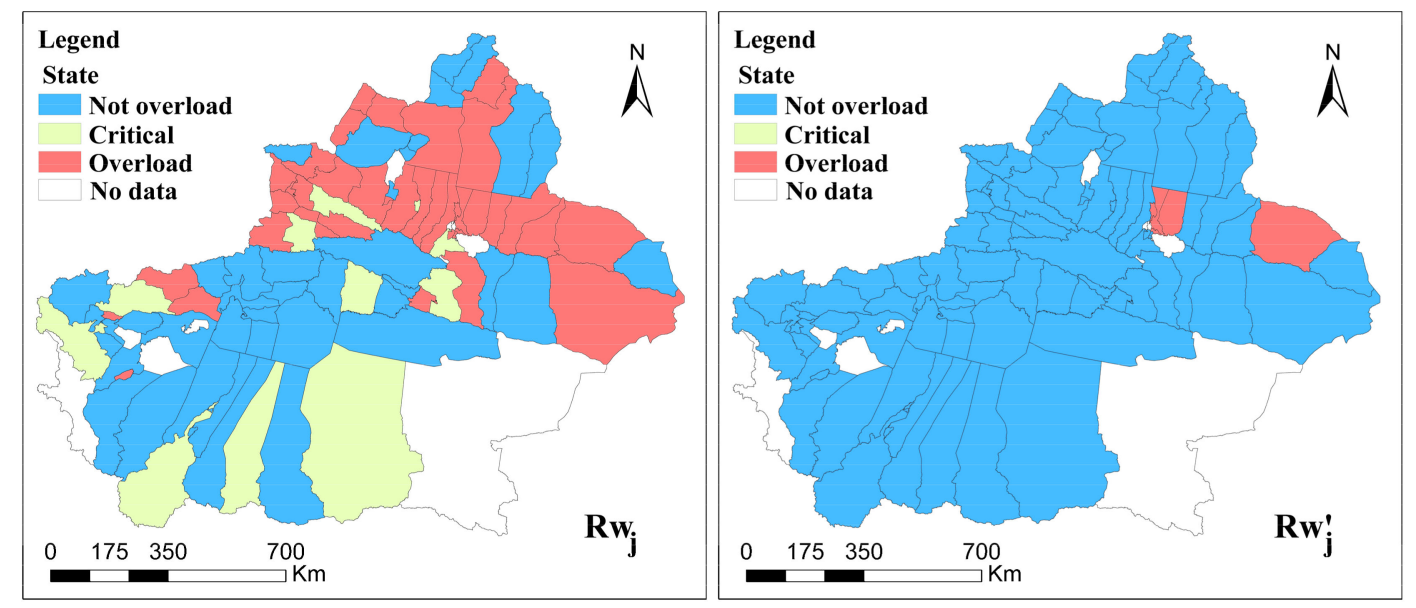

Figure 5. Evaluation results of the WECC. $\mathrm{Rw}_{j}$ is the WECC based on the short board effect, while $\mathrm{Rw}_{j}{ }^{\prime}$ is the WECC based on the weighted average.

\subsubsection{Weighted Average}

According to Formulas (9) and (10), the excess indices of the seven kinds of water pollutant concentrations in Xinjiang were calculated and used to characterize the WECC. The calculation results 
are shown in Figure $5-\mathrm{Rw}_{j}{ }^{\prime}$. Among the 89 counties and cities with water monitoring points, the degree of overload of the WECC was relatively good. Overloaded counties and cities accounted for $6 \%$ of the total in Xinjiang. Five counties and cities had WECC overloads, namely, Wujiaqu City, BKAC, Fukang City, and the Midong and Shuimogou Districts. In addition, 84 of the counties and cities were not overloaded, and none were critically overloaded.

\subsubsection{Comparative Analysis}

Based on the short board effect, in regards to the WECC, the percentages of overloaded, critically overloaded and not overloaded counties and cities were $45 \%, 43 \%$ and $12 \%$, respectively. Combined with Figure 3, the main reason for the WECC overload was that TN exceeded the standard due to agricultural pollution. However, in Xinjiang, rivers and lakes account for less than $1 \%$ of the total area; additionally, in Xinjiang, the population density surrounding lakes and rivers is relatively low, and human settlements have a low impact. At the same time, the impact of TN on an ecosystem or environment is controversial. Some scholars have found that nitrogen additions can improve carbon storage $[44,56]$ and increase the litter content of vegetation $[57,58]$. However, some scholars have found that nitrogen additions can reduce the carbon storage of ecosystems [59] and inhibit litter decomposition [45]. In addition, other scholars have discovered that although nitrogen additions can increase vegetation productivity, litter inputs from aboveground leaves and underground roots have no significant positive feedback effects on nitrogen additions [46,60]. For Xinjiang, the increase in nitrogen may have been beneficial $[47,61]$. In regards to the WECC, the weighted average results show that the percentages of overloaded, critically overloaded and not overloaded counties and cities were $6 \%, 0 \%$ and $94 \%$, respectively. Compared with the short board effect, the percentage of WECC overloaded counties and cities based on the weighted average decreased by $87 \%$, which eliminated the extreme impact of TN. In addition, the cumulative effects of industry, i.e., high pollution, high energy consumption, high water consumption, inadequate sewage collection and treatment facilities and relatively antiquated technology, caused WECC overloads in BKAC, Fukang City, and the Midong District and Shuimogou District of Urumqi City.

\subsection{Assessment of the CECC}

\subsubsection{Short Board Effect}

According to Formula (11), the over standard index of the air and water pollutant concentration was calculated and used to characterize the CECC. The calculation results are shown in Figure 6-Rw ${ }_{j}$. In the 91 counties and cities with atmospheric and water monitoring points, the CECC was seriously overloaded, and the environmental quality was worrying. A total of 46,10 , and 35 counties and cities that were overloaded, critically overloaded, and not overloaded, respectively. In addition, based on the spatial distribution, the overloaded counties and cities were mainly located in the Yili River Valley, the Wuchang Urban Agglomeration and other areas in northern Xinjiang. The critically overloaded counties and cities were mainly located in the Hetian and Kashgar areas, while the counties and cities that were not overloaded were mainly located in the Aksu area.

\subsubsection{Weighted Average}

According to Formula (12), the over standard index of the air and water pollutant concentration was calculated and used to characterize the CECC. The calculation results are shown in Figure 6-R $\mathrm{w}_{\mathrm{j}}{ }^{\prime}$. In the 91 counties and cities with atmospheric and water monitoring points, the degree of CECC overload was relatively weak, and the overall environmental quality was better. There were eight counties and cities with a CECC overload, including BKAC, Fukang City, Kashgar City, Wujiaqu City, Hetian City, and the Midong, Xinshi and Shuimogou Districts of Urumqi City. In addition, there were 83 counties and cities without overloads, and there were no critically overloaded counties and cities. 


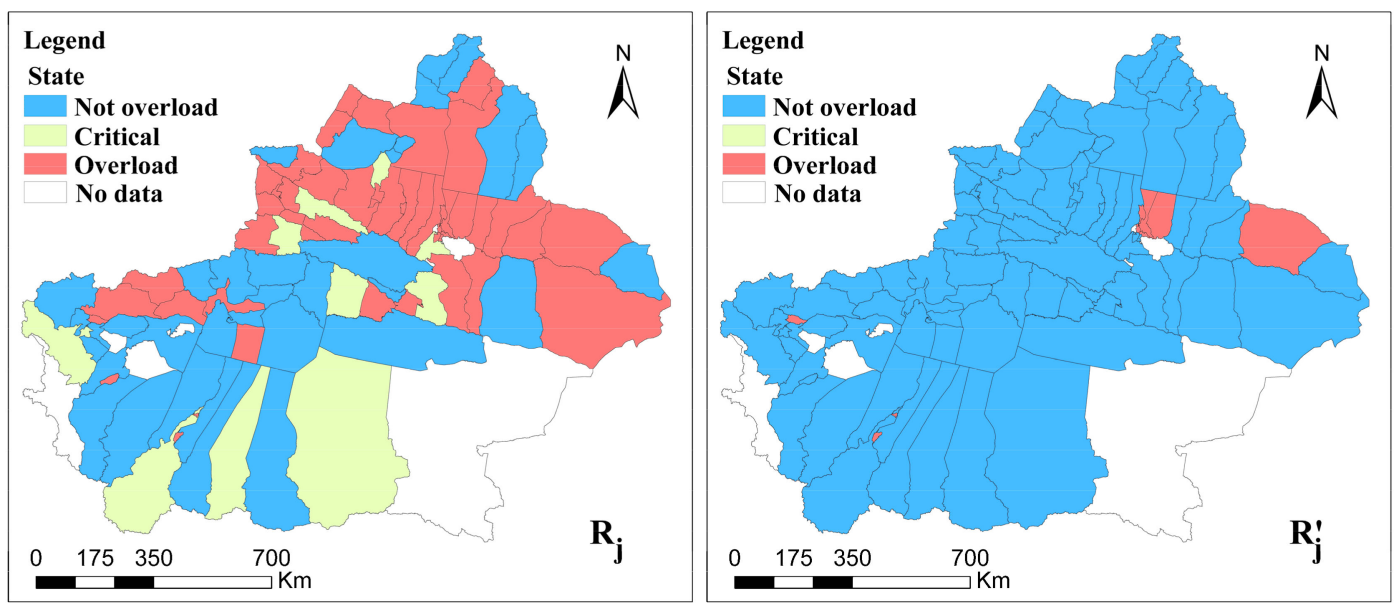

Figure 6. Evaluation results of the comprehensive environmental carrying capacity. $\mathrm{R}_{j}$ is the CECC based on Short board effect, while $\mathrm{R}_{j}{ }^{\prime}$ is the CECC based on Weighted average.

\subsubsection{Comparative Analysis}

The percentages of overloaded, critically overloaded and not overloaded counties and cities based on the short board effect were $51 \%, 11 \%$ and $38 \%$, respectively, while the percentages of overloaded, critically overloaded and not overloaded counties and cities based on the weighted average were $7 \%$, $0 \%$ and $93 \%$, respectively. Compared with those based on the short board effect, the percentages of overloaded counties and cities based on the weighted average of the CECC decreased by $86 \%$.

\subsection{Applicability Analysis of the Methods}

The short board effect-based evaluation of EQSs is mainly a comprehensive evaluation method that considers single atmospheric and water pollutant indices. The most direct and significant effect of the ECC on sustainable development is the short board effect. That is, a key factor that restricts regional development may directly determine the overall carrying capacity. Identifying the short board can reveal the crux of the contradiction between sustainable development and the environment [62]. The evaluation results of the AECC, WECC and ECC in Xinjiang show that the short board effect-based method is adopted in the evaluation of the element layer and comprehensive evaluation of the elements, which makes the degree of overload of the AECC, WECC and ECC in Xinjiang more serious and exacerbates the impact of $\mathrm{PM}_{2.5}, \mathrm{PM}_{10}$ and $\mathrm{TN}$ on the environment. This evaluation result will inevitably affect the formulation of regional development and environmental policies. China clearly stated in the "Suggestions" that stricter policy provisions, such as stricter emission permit requirements for overloaded areas, would be enacted, which may affect regional socioeconomic development.

From the research results, the evaluation results of a single index objectively reflected the main problems of the regional environment. These problems could be effectively controlled by special governance methods to better meet the needs of future regional development. In the evaluation of the factor levels and the comprehensive evaluation of the factors, the impacts of some environmental indicators will be strengthened using the short board effect method. However, the weighted average method can effectively weaken the impacts of individual indicators and more objectively reflect the overall environmental situation of a region, thus effectively improving the scientific basis underlying relevant environmental policy formulation. In addition, because the mechanism of environmental impact of different pollutants in arid regions has not been clarified, we assume that the weight of each pollutant is 1 , which has certain limitations. In future research, we will strengthen the analysis of the mechanism of the impact of different pollutants on the environment in different geographical areas and determine the weights of different pollutants in the RECC evaluation system to make the evaluation results more objective and reasonable. 


\section{Conclusions and Implications}

\subsection{Conclusions}

As an important basis for determining the degree of coordinated development of the human-land relationship in a country or region, the ECC holds great significance for promoting solutions to air and water pollution and for coordinating regional economic and social activities and the sustainable development of the ecological environment. Using atmospheric and water monitoring data, we calculated the concentration overload indices for the AECC, WECC and CECC of Xinjiang based on the short board effect and the weighted average. The main conclusions are as follows.

(1) $\mathrm{PM}_{2.5}$ and $\mathrm{PM}_{10}$ were the main factors that exceeded the atmospheric environmental standard; they are closely related to drought, low rainfall amounts, wind and sand in the natural environment of Xinjiang. TN was the main factor that exceeded the water environmental standard and was the key water environmental factor in Xinjiang.

(2) Based on a comparative study of the short board effect and weighted average methods, an evaluation of EQSs based on the weighted average was adopted in the factor layer, which was more suitable for evaluating the ECC in Xinjiang.

(3) There are great differences in the natural environments of China. In the RECC evaluation, the short board effect was used in the environmental assessment from the element level to amplify the environmental constraints. The weighted average evaluation was used in the element-level assessment, while the short board effect evaluation was used in the comprehensive integration. This practice effectively prevented the influence of non-key factors from being amplified, and thus, more objective and reasonable final evaluation results were obtained.

\subsection{Implications}

According to the evaluation results and analyses of the AECC, WECC and CECC, the following suggestions are proposed.

With respect to atmospheric environmental management, we should actively apply comprehensive prevention and control measures to the atmospheric environment and respond to heavy pollution levels, for example, effectively controlling industrial waste gas emissions and promoting the transitions from coal to gas and from coal to electricity. Additionally, we suggest promoting the use of clean, low-carbon fuels and optimizing urban traffic structures, such as those in Urumqi City. Moreover, environmental monitoring and governance should be further strengthened during the construction process.

Regarding control of the water environment, we should first strengthen the control of agricultural and rural pollution in Xinjiang, for example, reducing the use of pesticides and chemical fertilizers and reducing agricultural nonpoint source pollution. Second, we should fully implement the water function zoning and classification management of important rivers and lakes in Xinjiang, for example, strictly supervising and managing water function zones and the sewage outlets entering rivers and lakes, and we should resolutely ban industrial sewage outlets.

Concerning comprehensive environmental management, in view of the overloaded counties and cities in Xinjiang and their main over standard indicators, we should develop special treatments and define a time limit for pollution control. Concerning critically overloaded counties and cities, comprehensive management and environmental pollution prevention should be strengthened. For counties and cities that are not overloaded, we should continue to strictly control environmental checkpoints to avoid serious environmental problems.

Author Contributions: Conceptualization, F.X and D.Y.; Data curation, Z.Z., T.C. and R.W.; Formal analysis, Z.Z.; Funding acquisition, F.X.; Methodology, F.X. and D.Y.; Writing—original draft, Z.Z.; Writing—review \& editing, Z.Z., F.X., Y.Z., T.C. and R.W.

Funding: This research was funded by National Science and Technology Support Program Project "Research on Xinjiang's Strategies for Scientific and Technological Development to Address Climate Change" (No. 2012BAC20B09). 
Acknowledgments: This work also was supported by the Local Commissioned Subject "Study on Monitoring and Early Warning of Resources and Environment Bearing Capacity in Xinjiang". The authors sincerely thank the reviewers and editors.

Conflicts of Interest: The authors declare no conflict of interest.

\section{References}

1. Ebenstein, A.; Fan, M.; Greenstone, M.; He, G.; Zhou, M. New evidence on the impact of sustained exposure to air pollution on life expectancy from China's Huai River Policy. Proc. Natl. Acad. Sci. USA 2017, 114, 10384-10389. [CrossRef] [PubMed]

2. Sun, S.; Tian, L.; Cao, W.; Lai, P.C.; Wong, P.P.Y.; Lee, R.S.Y.; Mason, T.G.; Krämer, A.; Wong, C.M. Urban climate modified short-term association of air pollution with pneumonia mortality in Hong Kong. Sci. Total Environ. 2019, 646, 618-624. [CrossRef] [PubMed]

3. Jiang, Y. China's water scarcity. J. Environ. Manag. 2009, 90, 3185-3196. [CrossRef] [PubMed]

4. Zuo, Q.; Jin, R.; Ma, J.; Cui, G. China pursues a strict water resources management system. Environ. Earth Sci. 2014, 72, 2219-2222. [CrossRef]

5. Kiesewetter, G.; Schoepp, W.; Heyes, C.; Amann, M. Modelling PM2. 5 impact indicators in Europe: Health effects and legal compliance. Environ. Model. Softw. 2015, 74, 201-211. [CrossRef]

6. Malthus, T.R. An Essay on the Principle of Population; Cambridge University Press: Cambridge, UK, 1826.

7. Park, R.E.; Burgess, E.W. Introduction to the Science of Sociology; University of Chicago Press: Chicago, IL, USA, 1924; Volume 574.

8. Bishop, A.B. Carrying Capacity in Regional Environmental Management; U.S. Government Printing Office: Washington, DC, USA, 1974; Volume 1.

9. Zeng, W.; Wang, H.; Xue, J.; Ye, W.; Guan, B.; Mei, F. Environmental carrying capacity: A key to the coordination of the development of population, resources and environment. China Popul. Resour. Environ. 1991, 1, 33-37. (In Chinese)

10. Peng, Z. The primary exploring of the research method of AESC. China Environ. Sci. 1996, 16, 6-10. (In Chinese)

11. Feng, Z.; Yang, Y.; Yan, H. A review of resources and environment carrying capacity research since the 20th Century: From theory to practice. Resour. Sci. 2017, 39, 379-395. (In Chinese)

12. Wang, J.; Sun, T.Y.; Li, P.J.; Li, F.Y. Research progress on environmental carrying capacity. J. Appl. Ecol. 2005, 16, 768-772. (In Chinese)

13. Wang, C.; Feng, L.; Luo, W. Comprehensive evaluation of carrying capacity of water resources in Yangtze River Delta. J. Water Resour. Water Eng. 2012, 4, 38-42. (In Chinese)

14. Wei, C.; Guo, Z.; Wu, J.; Ye, S. Constructing an assessment indices system to analyze integrated regional carrying capacity in the coastal zones-A case in Nantong. Ocean Coast. Manag. 2014, 93, 51-59. [CrossRef]

15. Zheng, D.; Zhang, Y.; Zang, Z.; Sun, C. Empirical research on carrying capacity of human settlement system in Dalian City, Liaoning Province, China. Chin. Geogr. Sci. 2015, 25, 237-249. [CrossRef]

16. Peng, J.; Du, Y.; Liu, Y.; Hu, X. How to assess urban development potential in mountain areas? An approach of ecological carrying capacity in the view of coupled human and natural systems. Ecol. Indic. 2016, 60,1017-1030. [CrossRef]

17. Zhang, F.; Wang, Y.; Ma, X.; Wang, Y.; Yang, G.; Zhu, L. Evaluation of resources and environmental carrying capacity of 36 large cities in China based on a support-pressure coupling mechanism. Sci. Total Environ. 2019. [CrossRef] [PubMed]

18. Wackernagel, M.; Yount, J.D. The ecological footprint: An indicator of progress toward regional sustainability. Environ. Monit. Assess. 1998, 51, 511-529. [CrossRef]

19. Thébault, J.; Schraga, T.S.; Cloern, J.E.; Dunlavey, E.G. Primary production and carrying capacity of former salt ponds after reconnection to San Francisco Bay. Wetlands 2008, 28, 841-851. [CrossRef]

20. Sutton, P.C.; Anderson, S.J.; Tuttle, B.T.; Morse, L. The real wealth of nations: Mapping and monetizing the human ecological footprint. Ecol. Indic. 2012, 16, 11-22. [CrossRef]

21. Jung, C.; Kim, C.; Kim, S.; Suh, K. Analysis of Environmental Carrying Capacity with Emergy Perspective of Jeju Island. Sustainability (Basel) 2018, 10, 1681. [CrossRef] 
22. Davies, E.G.; Simonovic, S.P. Global water resources modeling with an integrated model of the social-economic-environmental system. Adv. Water Resour. 2011, 34, 684-700. [CrossRef]

23. Wang, Y.; Zhou, X.; Engel, B. Water environment carrying capacity in Bosten Lake basin. J. Clean. Prod. 2018, 199, 574-583. [CrossRef]

24. Wang, W.; Zeng, W. Optimizing the regional industrial structure based on the environmental carrying capacity: An inexact fuzzy multi-objective programming model. Sustainability (Basel) 2013, 5, 5391-5415. [CrossRef]

25. Xue, W.; Fu, F.; Wang, J.; He, K.; Lei, Y.; Yang, J.; Wang, S.; Hang, B. Modeling study on atmospheric environmental capacity of major pollutants constrained by $\mathrm{PM}_{2.5}$ compliance of Chinese cities. China Environ. Sci. 2014, 34, 2490-2496. (In Chinese)

26. Li, N.; Yang, H.; Wang, L.; Huang, X.; Zeng, C.; Wu, H.; Ma, X.; Song, X.; Wei, Y. Optimization of industry structure based on water environmental carrying capacity under uncertainty of the Huai River Basin within Shandong Province, China. J. Clean. Prod. 2016, 112, 4594-4604. [CrossRef]

27. Liu, R.; Borthwick, A.G. Measurement and assessment of carrying capacity of the environment in Ningbo, China. J. Environ. Manag. 2011, 92, 2047-2053. [CrossRef] [PubMed]

28. Pandey, V.P.; Babel, M.S.; Shrestha, S.; Kazama, F. A framework to assess adaptive capacity of the water resources system in Nepalese river basins. Ecol. Indic. 2011, 11, 480-488. [CrossRef]

29. Nianlei, L.; Yaling, L.; Hongqiang, J.; Xi, C. Environmental carrying capacity evaluation methods and application based on environmental quality standards. Prog. Geogr. 2017, 36, 296-305. (In Chinese)

30. Yang, J.; Lei, K.; Khu, S.; Meng, W.; Qiao, F. Assessment of water environmental carrying capacity for sustainable development using a coupled system dynamics approach applied to the Tieling of the Liao River Basin, China. Environ. Earth Sci. 2015, 73, 5173-5183. [CrossRef]

31. Zeng, W.; Wu, B.; Chai, Y. Dynamic simulation of urban water metabolism under water environmental carrying capacity restrictions. Front. Environ. Sci. Eng. 2016, 10, 114-128. [CrossRef]

32. Carey, D.I. Development based on carrying capacity: A strategy for environmental protection. Glob. Environ. Chang. 1993, 3, 140-148. [CrossRef]

33. Lane, M. The carrying capacity imperative: Assessing regional carrying capacity methodologies for sustainable land-use planning. Land Use Policy 2010, 27, 1038-1045. [CrossRef]

34. Du, J.; Shu, J.; Yin, J.; Yuan, X.; Jiaerheng, A.; Xiong, S.; He, P.; Liu, W. Analysis on spatio-temporal trends and drivers in vegetation growth during recent decades in Xinjiang, China. Int. J. Appl. Earth Obs. 2015, 38, 216-228. [CrossRef]

35. Wu, Z.; Zhang, H.; Krause, C.M.; Cobb, N.S. Climate change and human activities: A case study in Xinjiang, China. Clim. Chang. 2010, 99, 457-472. [CrossRef]

36. Yushanjiang, A.; Zhang, F.; Yu, H. Quantifying the spatial correlations between landscape pattern and ecosystem service value: A case study in Ebinur Lake Basin, Xinjiang, China. Ecol. Eng. 2018, 113, 94-104. [CrossRef]

37. Mamat, Z.; Yimit, H.; Eziz, A.; Ablimit, A. Oasis land-use change and its effects on the eco-environment in Yanqi Basin, Xinjiang, China. Environ. Monit. Assess. 2014, 186, 335-348. [CrossRef] [PubMed]

38. Abulizi, A.; Yang, Y.; Mamat, Z.; Luo, J.; Abdulslam, D.; Xu, Z.; Zayiti, A.; Ahat, A.; Halik, W. Land-use change and its effects in Charchan Oasis, Xinjiang, China. Land Degrad. Dev. 2017, 28, 106-115. [CrossRef]

39. Lei, X.; Lu, J.; Liu, Z.; Tong, Y.; Li, S. Concentration and distribution of antibiotics in water-sediment system of Bosten Lake, Xinjiang. Environ. Sci. Pollut. Res. 2015, 22, 1670-1678. [CrossRef]

40. Liu, J.; Yao, X.; Lu, J.; Qiao, X.; Liu, Z.; Li, S. Distribution and factors affecting adsorption of sterols in the surface sediments of Bosten Lake and Manas Lake, Xinjiang. Environ. Sci. Pollut. Res. 2016, 23, 5892-5901. [CrossRef] [PubMed]

41. Zhan, D.; Kwan, M.P.; Zhang, W.; Yu, X.; Meng, B.; Liu, Q. The driving factors of air quality index in China. J. Clean. Prod. 2018, 197, 1342-1351. [CrossRef]

42. Chinese Research Academy of Environmental Sciences; National Environmental Monitoring Centre. Ambient air quality standards. In China National Standards (CN-GB); Standardization Administration of China: Beijing, China, 2012; Volume GB 3095-2012.

43. Chinese Research Academy of Environmental Sciences. Environmental quality standards for surface water. In State Environmental Protection Administration of China; General Administration of Quality Supervision, Inspection and Quarantine of China: Beijing, China, 2002; Volume GB 3838-2002. 
44. LeBauer, D.S.; Treseder, K.K. Nitrogen limitation of net primary productivity in terrestrial ecosystems is globally distributed. Ecology 2008, 89, 371-379. [CrossRef]

45. Carreiro, M.; Sinsabaugh, R.; Repert, D.; Parkhurst, D. Microbial enzyme shifts explain litter decay responses to simulated nitrogen deposition. Ecology 2000, 81, 2359-2365. [CrossRef]

46. Zak, D.R.; Holmes, W.E.; Burton, A.J.; Pregitzer, K.S.; Talhelm, A.F. Simulated atmospheric NO3- deposition increases soil organic matter by slowing decomposition. Ecol. Appl. 2008, 18, 2016-2027. [CrossRef]

47. Huang, C.B.; Zeng, F.J.; Lei, J.Q. Cultivation effects on the carbon and nitrogen dynamics at depth in oasis farmlands of the Southern Tarim Basin, China. Soil Sci. Plant Nutr. 2015, 61, 287-294. [CrossRef]

48. Hou, X.; Fei, D.; Kang, H.; Zhang, Y.; Gao, J. Seasonal statistical analysis of the impact of meteorological factors on fine particle pollution in China in 2013-2017. Nat. Hazards 2018, 93, 677-698. [CrossRef]

49. Ye, W.F.; Ma, Z.Y.; Ha, X.Z. Spatial-temporal patterns of $\mathrm{PM}_{2.5}$ concentrations for 338 Chinese cities. Sci. Total Environ. 2018, 631, 524-533. [CrossRef]

50. Wang, Y.; Zhang, J.; Bai, Z.; Yang, W.; Zhang, H.; Mao, J.; Sun, Y.; Ma, Z.; Xiao, J.; Gao, S. Background concentrations of PMs in Xinjiang, West China: An estimation based on meteorological filter method and Eckhardt algorithm. Atmos. Res. 2019, 215, 141-148. [CrossRef]

51. Yuhong, G. The summer dust weather occurred in the southern cities of Xinjiang, and the air quality was seriously polluted. Arid Environ. Monit. 2015, 29, 138. (In Chinese)

52. Shen, Y.; Zhang, L.; Fang, X.; Ji, H.; Li, X.; Zhao, Z. Spatiotemporal patterns of recent PM2. 5 concentrations over typical urban agglomerations in China. Sci. Total Environ. 2019, 655, 13-26. [CrossRef]

53. Chao, G.; Yuhong, G. Discussion of Quality Control Road-Inspection on PM10 Auto-Monitoring Instrument for City Environmental Air in Xinjiang. Arid Environ. Monit. 2010, 24, 34-38. (In Chinese)

54. Yuhong, G.; Chao, G. Under the Air Unattended Station Arid Area Sandstorm Weather Moves the Question and the Solution Which Exists. Arid Environ. Monit. 2010, 24, 181-185. (In Chinese)

55. Yuhong, G.; Zifa, W.; Hong, K.; Xiaoxiao, Z.; Yuan, J.; Jie, L.; Huansheng, C. Influence of monitoring index TSP and PM10 on ambient air quality grade at cities of Xinjiang, China. Arid Land Geogr. 2014, 37, 731-743. (In Chinese)

56. Thomas, R.Q.; Canham, C.D.; Weathers, K.C.; Goodale, C.L. Increased tree carbon storage in response to nitrogen deposition in the US. Nat. Geosci. 2010, 3, 13. [CrossRef]

57. Bradley, K.; Drijber, R.A.; Knops, J. Increased N availability in grassland soils modifies their microbial communities and decreases the abundance of arbuscular mycorrhizal fungi. Soil Biol. Biochem. 2006, 38, 1583-1595. [CrossRef]

58. Adamek, M.; Corre, M.D.; Hölscher, D. Early effect of elevated nitrogen input on above-ground net primary production of a lower montane rain forest, Panama. J. Trop. Ecol. 2009, 25, 637-647. [CrossRef]

59. Mack, M.C.; Schuur, E.A.; Bret-Harte, M.S.; Shaver, G.R.; Chapin, F.S., III. Ecosystem carbon storage in arctic tundra reduced by long-term nutrient fertilization. Nature 2004, 431, 440. [CrossRef]

60. Janssens, I.; Dieleman, W.; Luyssaert, S.; Subke, J.A.; Reichstein, M.; Ceulemans, R.; Ciais, P.; Dolman, A.J.; Grace, J.; Matteucci, G. Reduction of forest soil respiration in response to nitrogen deposition. Nat. Geosci. 2010, 3, 315. [CrossRef]

61. Kou, Y.; Li, J.; Wang, Y.; Li, C.; Tu, B.; Yao, M.; Li, X. Scale-dependent key drivers controlling methane oxidation potential in Chinese grassland soils. Soil Biol. Biochem. 2017, 111, 104-114. [CrossRef]

62. Fan, J.; Wang, Y.; Tang, Q. Academic thought and technical progress of monitoring and earlywarning of the national resources and environment carrying capacity (V 2014). Sci. Geogr. Sin. 2015, 35, 1-10. (In Chinese)

(C) 2019 by the authors. Licensee MDPI, Basel, Switzerland. This article is an open access article distributed under the terms and conditions of the Creative Commons Attribution (CC BY) license (http://creativecommons.org/licenses/by/4.0/). 